\title{
Intervening on Behalf of the Human Right to Health: Who, When, and How?
}

\author{
Kathryn Muyskens ${ }^{1}$
}

Accepted: 18 March 2021/ Published online: 28 March 2021

(C) Springer Nature B.V. 2021

\begin{abstract}
A common understanding of the political function of human rights is as a trigger for international intervention, with states typically understood to be duty bound by these rights claims. The unique character of the human right to health raises some complications for these conventional views. In this paper, I will argue that because of the unique character of the human right to health, intervention on its behalf can be justified not only in response to outright violation, but also due to unmet needs of populations. As a secondary goal of this paper, I will attempt to respond to some of the worries about cultural imperialism in human rights and cross-cultural humanitarian interventions, specifically in the context of global health justice.
\end{abstract}

Keywords Human rights $\cdot$ Health $\cdot$ Global health, Humanitarian aid

\section{Introduction}

One common understanding of human rights is as a trigger for intervention (see Beitz 2009, Buchanan 2010). This political function of human rights is the very thing which has often triggered the backlash against them - saying they are merely tools of Western imperialism. Discussion of human rights abuses as justifications for international interventions, the manner and method of those interventions, as well as objections to them are abundant in the philosophical literature (Tasioulas 2009, Viehoff 2013, Peterson 2006, just to name a few). So too is the literature on global health, public health, and the efficacy and ethics of aid (e.g., DeCamp 2005, Bellamy 2006, among others). However, the idea that the human right to health imposes a duty on charities and international non-governmental organizations (INGOs), not just states, has not previously been argued. In this article, I will argue that because of the unique character of the human right to health, intervention on its behalf can be justified not only in

Kathryn Muyskens

klmuyskens@yale-nus.edu.sg; klmuyskens@gmail.com

1 Yale-NUS College, 16 \#01-220, College Ave West, 138527 Singapore, Singapore 
response to outright violation but also due to unmet needs of populations. When the primary duty holders (i.e., states) are unable to meet the minimum standards demanded in a right to health, the obligation diffuses to the next most capable bodies, which can include humanitarian organizations and INGOs. That said, the manner and form of interventions on behalf of health will look decidedly different from other human right interventions.

Broadly speaking, reasons for states failing to meet the human right to health come in two kinds: (1) a state may be unable to meet its citizens' human right to health or (2) it may be unwilling to do so. Each kind of failure requires a different kind of response, and each kind of response comes with its own complications and limits. Because of the cross-cultural and international application, care must be taken to avoid the appearance of ethnocentric bias when claiming that a human right violation has occurred. Without such care, we risk reinforcing the narrative that human rights are merely justifications for Western imperial impositions.

Some may point out that the risk of cultural imperialism is not the only, and perhaps not even the most severe, ethical hazard facing humanitarian agencies and INGOs. Working across national boundaries can produce an accountability gap, for instance, if aid workers from one country transgress the laws or customs of the recipients of that aid. My focus on the issue of cultural imperialism within this article is not meant to imply that it is the only issue that needs addressing in this context. It is, however, an important issue - and one all too often neglected. Without addressing the moral hazards presented by cultural imperialism, we risk undermining the perceived legitimacy and moral force of international human rights norms the world over.

For the purposes of this article, I will be relying on the definition of cultural imperialism provided by Lisa Fuller in her 2012 paper "International NGO Health Programs in a Non-Ideal World: Imperialism, Respect, and Procedural Justice.” The term originates from the colonial era, where "Western nations set out to conquer and rule territories in North America, Asia, and Africa for the dual purpose of exploiting their natural resources and 'civilizing' their inhabitants" (Fuller 2012, 217). Fuller describes three key features of this kind of cultural imperialism: (1) intent to dominate and reform the beliefs of others, (2) belief that their own (Western) culture is inherently superior, and (3) the use of coercive measures to carry out this task $(2012,217)$.

The wrongfulness of cultural imperialism, she claims, is not that it exports values of any particular kind, but that it undermines the autonomy of the less powerful group. She acknowledges that "these features do not appear - at first glance anyway - to apply in the context of delivering medical aid in the present day," in that INGO workers do not aim to dominate or impose on others, nor are they likely to believe in the inherent superiority of Western culture (Fuller 2012).

However, Fuller argues that in modern times cultural imperialism need not be intentional, and its perpetrators need not believe they are superior or entitled. The coercive activity alone, and the resultant injury to the autonomy of the recipient groups, in the form of their values being "replaced" or "supplanted" is sufficient. Fuller and those who would agree with her think that coercive interventions are always (at least culturally) imperialistic and therefore wrong. However, I will argue that in at least some cases, coercive interventions can be justified, and human right interventions, properly done, do not fit the criteria to be considered culturally imperialistic. 


\section{The Impetus for Intervention: Violation and Unmet Needs}

I take as a starting assumption of my arguments here that human rights are best thought of as political instruments, a view defended by political philosophers like Charles Beitz (2009), Allen Buchanan (2010), and Jonathan Wolff (2012). Additionally, I endorse the view that one of the functions of human rights is to justify international political intervention when they are violated. When a state fails in its duty to respect human rights, it loses legitimacy, opening it to criticism and interference from other states to remedy the problem. This, however, is a continuing source of conflict, owing to the suspicion that human rights are merely excuses for Western imperialistic agendas. Thus, it is important to articulate guidelines that help identify violations and pair these with appropriate responses in as culturally neutral a way as possible.

\section{Cross-Cultural Complications}

It is common to assume that health is a universal and uncontroversial good. While I think this is true, health is also a culturally laden concept. This means that crosscultural judgments about what violates a human right to health can be complicated by the different conceptualizations of health that underpin different societies' health policies.

In the modern era, most disavow the old crusader/colonial mentality that gave excuse to so much violence in the recent past. Despite this, political philosophers like William Sullivan and Will Kymlicka (2007) have pointed out that the currently fashionable view is not always sufficiently different. They point out that the old colonial powers did not justify their actions on a supposed right to impose their views on others. Rather, colonizing forces (like the Catholic Spanish) perceived the practices of the societies they colonized (like the Aztecs) as falling below a minimally decent moral standard (Sullivan and Kymlicka 2007). To the Spanish, many Aztec practices, like human sacrifice, seemed plainly barbaric. Kymlicka notes that few people would disagree with the Spanish today for suppressing the practice of ritualized murder. Yet, the Spanish also perceived other Aztec practices as falling below the minimal standard which seem less uncontroversial today, like the Aztec convention of tracing matrilineal kinship (Sullivan and Kymlicka 2007).

With such examples, Kymlicka seeks to caution modern human rights activists from making similar ethnocentric judgments. While we promote human rights, we are often quick to identify practices we perceive to be barbaric in cultures not our own, but fail to see the way in which our own practices may be conceived as barbaric by others.

Human rights intervention in practice has not always avoided these biases. But at least in the creation of international documents, like the The Universal Declaration of Human Rights, UDHR (n.d.) and International Covenant on Economic, Social and Cultural Rights, n.d. (ICESCR), despite the political power of Britain and the United States, "intensive lobbying by Carlos Romulo of the Philippines, Herbert Evatt of Australia, and philosophy professor Charles Malik of the Lebanese Republic, together with several Latin American states, led to concerns of less powerful nations and their peoples coming to the fore" (Wolff 2012, 3-4). Since the documents themselves were created through cross cultural dialogue, they provide a good basis on which to begin the discussion. 


\section{Terminology and Tensions}

To better understand what it means for the human right to health to be met or violated, it is helpful to look at how the right has been articulated in international documents like the UDHR and ICESCR. The UDHR states in Article 25.1, "Everyone has the right to a standard of living adequate for the health of himself and of his family, including food, clothing, housing and medical care and necessary social services." Article 12 of ICESCR proclaims the "the right of everyone to the enjoyment of the highest attainable standard of physical and mental health." The later addition of General Comment 14 elaborates to say that the "right to health is not to be understood as a right to be healthy." General Comment 14 is also specific in pointing out that the United Nations General Assembly did not adopt the conception of health articulated in the Constitution of the World Health Organization (WHO) (where health is a state of complete physical, mental, and social well-being and not merely the absence of disease or infirmity). General Comment 14 does however insist that the right to health is not merely the right to health care, but also the right to the underlying determinants of health, such as food and nutrition, housing, safe water, sanitation, etc.

General Comment 14 also makes explicit the freedoms and entitlements that a human right to health entails. These freedoms include, "the right to control one's health and body, including sexual and reproductive freedom, and the right to be free from interference, such as the right to be free from torture, non-consensual medical treatment and experimentation" (“General Comment 14 n.d."). The entitlements listed "include the right to a system of health protections which provides equality of opportunity for people to enjoy the highest attainable level of health" ("General Comment 14 n.d.").

Recognizing the existence of resource constraints, the ICESCR adopts the view of "progressive realization" rather than "full immediate realization" of the right to health. Yet, the phrase "progressive realization," especially when used in combination with another of the human right to health's key terms, "minimum core obligations," can be perplexing at best. As Jonathan Wolff (2012) explains, “'[p]rogressive realization' permits a country's limited resources to provide a valid excuse for limited progress to full realization, whereas the notion of 'minimum core obligations' suggests that there is no excuse for failing to achieve a particular level of health care" (11). These two phrases seem initially to be in tension.

The source of the tension arises from the idea that "ought" implies "can." I take the view that two things are necessary for something to be considered a violation of the right to health-(1) the existence of a feasible alternative and (2) a lack of justifiable cause for that alternative not being taken. Both are predicated on the presence of a political institution capable of acting in the first place.

So, how should we understand where the minimum core obligations stop and the domain of progressive realization begins? The ICESCR lists the following as part of the minimum core obligations: (1) non-discriminatory access to health facilities, (2) access to "minimum essential food which is nutritionally adequate and safe," (3) access to "basic shelter, housing, and sanitation," (4) equitable distribution of all health facilities, goods, and services, and (5) implementation of a "national public health strategy ... addressing the concerns of the whole population" (Tasioulas 2017a). Other aspects of the right to health, including reproductive health, prevention of epidemics, and 
appropriate training for healthcare personnel (just to name a few) are thus left to be "progressively realized."

However, some tension still seems to need working out. Recent literature on the topic by John Tasioulas $(2017 \mathrm{a}, 2017 \mathrm{~b})$ has interpreted the "minimum core obligations" (or as he abbreviates it, MCD - for "Minimum Core Doctrine") as demanding immediate and full compliance, meaning "progressive realization" cannot be used to excuse unmet standards in these areas. However, I would contend that while a willing and compliant state may be able to meet some of these obligations quickly (nondiscriminatory access to health resources, e.g., could possibly be written immediately into law), in some aspects, such "immediate" and "full" compliance seems an unreasonably high bar. Infrastructure that provides safe water, housing, sanitation, and food can take years to build, even with the best of efforts. This is precisely the problem the human right to health is meant to address - the fact that in some corners of the world, people live without the basic ingredients for a minimally decent human life. Yet, they do not always lack these things through the results of persecution or malice. It must be admitted that it is not always within a given state's power to immediately provide its people with these core obligations - especially those that are subject to resource constraints. For instance, it may be immediately possible to commit to public policies, to make illegal any discrimination, etc., but if there is insufficient food, water, sanitation, housing, healthcare infrastructure, etc., this still requires time to remedy, and quite possibly also aid.

The human right to health is supposed to protect people from standard threats to health - standard threats being urgent, predictable, preventable injuries. On that definition, famines could be a violation of rights, but only if the famines are caused by mismanaged resources and not unpredictable and unpreventable natural disasters. Similarly, deaths because of finite health resources are not violations of the human right to health. But scarce resources cannot be an excuse to give preferential access to healthcare based on race or gender, since that fails to treat humans with equal dignity. Saying some action violated people's rights must mean that there is some blameworthy reason why the institution did not meet its obligations. The tragic and the unfortunate are not by themselves violations of rights. Thus, it seems possible to resolve the tension in these terms by understanding that the MCD is meant to prevent "progressive realization" from becoming a loop-hole for derelict or negligent actors. However, because of the nature of health and the positive duties imposed by the human right, outright right violations are not the only possible failures. The issues of resource constraints and the resulting health gaps still need an answer.

\section{Positive Duties, Unmet Needs}

The human right to health's status as a positive right (as opposed to a negative right) adds further dimensions for consideration. Unlike a right not to be tortured, which requires only that others abstain from the act, the human right to health imposes a positive duty on political institutions. While negative rights protect a person's freedoms from interference from others (like a right to free speech, freedom of association, or religious affiliation), positive rights impose burdens and duties upon others to meet the rights of the claimant. This aspect raises further complications for the plausibility and feasibility of a right, given the concerns of what may be reasonable or possible to 
demand. This is a feature which has led some critics to doubt that there can be such a thing as a human right to health at all. For instance, Gopal Sreenivasan raises this worry in his 2012 article "A Human Right to Health: Some Inconclusive Skepticism,"

According to a familiar argument, sometimes called the 'claimability objection', positive claim-rights are less well-founded than negative claim-rights. 8 Positive claim-rights (e.g. a right to health) are rights to some action by a correlative dutybearer (e.g. to her preserving the health of the right-holder), whereas negative claim-rights (e.g. a right against torture) are rights to some forbearance by a correlative duty-bearer (e.g. to his refraining from torturing the right-holder). Positive claim-rights are meant to be less well-founded because in many cases it is unclear who bears the correlative duty (and hence unclear whether anyone does). If no one has the correlative duty, then (on the standard definition, anyhow) there is no right: no claim can be made. (243)

But other thinkers, like Jonathan Wolff (2012), have pointed out that even so-called negative rights impose similar positive burdens on political institutions. A right to not be tortured still requires that the state supplies police to enforce the law, and other institutions capable of responding if the right is violated. Just as we do not blame the government for every crime that occurs in a community, we cannot blame a government for every preventable illness either. However, we would consider it at fault if people were regularly murdered because no police force was in place to prevent it, or no legal system was present to bring murderers to justice. Logically, we could consider the state similarly to blame if its citizens regularly died of easily preventable illnesses because it did not have any infrastructure in place to prevent these deaths. But the culpability of the state in these kinds of scenarios is entirely dependent on the perceived ability of the government to prevent the deaths. If a government can prevent deaths from disease, and yet neglects to make any effort to do so, this would be a violation of its people's human rights.

There is a dis-analogy between a right to health and a right not to be tortured. If no one is committing torture, then it is safe to assume that there is also no one being tortured. But that is not the case with health-just because no one is purposively injuring health does not mean that no one's health is injured. As a positive right, violations can occur not just through commission but through omission as well. If political institutions are the parties responsible for upholding human rights, then when a state is unable to meet the minimum health needs of its people, is this a violation? If ought implies can, then no. Indeed, it would seem that neither of the previously mentioned criteria for violation has been met. If a state is unable to provide healthcare or basic health inputs through no choice of its own, the health needs of its citizens go unmet, with no one to blame. Violations of human rights are thought to provide justification for international intervention. Unmet needs are not violations. But all this leaves underdetermined what ought to be done when states have failed, or when people have been robbed of a state to which they can belong, like refugees. This presents a problem for human rights, which are supposed to apply to all people - not just citizens of capable states. To remedy this gap, I will argue that in cases where the minimum core standards of health are not met and the normal institutions are not capable or present, then this too can justify intervention. Stateless people, refugees, and those 
living in failed states still have the same human rights, including a right to health and healthcare. But who can they appeal to, and what form of intervention is justified?

\section{Aiding the Unable}

The human right to health is in a unique situation as compared to other human rights. Sometimes the institutions responsible for meeting and protecting the right will be absent or incapable. But just because the people are left without an obvious institutional alternative does not mean they do not still hold a right to the freedoms and entitlements included in the human right to health. In lieu of the usual institutions, I will argue, the duty to respond diffuses to the next most capable body, which at least in some cases will be a humanitarian health organization or INGO. Intervening in such cases carries with it some unique factors that create certain moral risks, like undermining the autonomy of the aid recipients, creating unintentionally coercive offers, and the exacerbating of cycles of dependency.

\section{Diffusion of Duties and the Responsibility to Protect}

Peter Singer $(1972,2009)$ has argued that we have ethical duties to help others regardless of their proximity to us. The suffering of another person and our ability to help them are not diminished by distance. While he does not build his arguments in terms of human rights, many of his points still find application when discussing human rights in connection with the issues of global health.

The nature of health provides several considerations that I will argue which give us reason to believe that the duties imposed by the human right to health extend beyond the relationship between citizens and states. Many aspects of health simply cannot be adequately managed by any single state in isolation. Infectious illnesses, famines, and other threats to health do not respect arbitrary borders between states. If such kinds of threats to health emerge in states that are too resource-poor to combat them on their own, wealthier states and/or INGOs have strong reason to make up the difference, including altruism, solidarity (the recognition that we're all in this fight together), and simple self-interest (Emerson and Singer 2010).

Here, some may object by pointing out that there is a dis-analogy between the responsibility of a private citizen to help another private citizen through charity (as Singer advocates) and the responsibility of a private group to interfere in the operations of a sovereign state. Sovereignty, after all, has important political functions and is a norm that should not be lightly disregarded, as Wim De Ceukelaire and Marc Johan Botenga (2014) write in a brief article in The Lancet, revealingly titled "On Global Health: Stick to Sovereignty." In this piece, the authors respond to the claim that in tackling global health, the "global village" might substitute for state sovereignty, saying "without an effective regulatory framework the right to health is rendered virtually meaningless" (De Ceukelaire and Botenga 2014, 951). Within the regulatory framework provided by states, right-based discourse has the necessary force to create real improvements. In contrast, they argue, weakening the state's role "will probably benefit transnational corporations more than it will benefit public health" (De Ceukelaire and Botenga 2014, 952). 
An additional worry that arises in diffusing human rights obligations to INGOs and charities is that these organizations have typically been conceived as apolitical. Indeed, this apolitical status is what enables them to carry out their humanitarian missions in ways that states cannot. However, other scholars, such as Andrew Clapham (2006), have argued that the old norms of international human rights laws applying exclusively to states are outdated. Much about the modern political landscape is challenging this old model, and human rights activists are already being forced to adapt. As Clapham (2006) discusses in his article "Human Rights Obligations of Non-State Actors in Conflict Situations," there is already precedent for holding non-state actors accountable for human rights violations as well as imposing obligations to respect human rights norms on non-state agents. Though his article is primarily focused on insurgents, belligerents, and national liberation movements, he argues, "[i]f we fail to address our human rights concerns to these non-state actors, we fail the victims of the abuses. It is time to feel comfortable talking about the human rights obligations of non-state actors" (Clapham 2006, 523). Clapham (2006) observes that there is already precedent for holding corporations accountable for human rights violations (in the USA) and even private individuals (as in the case of torture in Yugoslavia) - and though he mostly discusses this in the context of armed conflicts - the general message, that the language and application of human rights increasingly need to be able to account for "unofficial" and "non-state" actors, seems readily applicable to the domain of humanitarian aid and global health (515).

There are many new challenges to human rights that are occurring all the time and there are some reasonable worries if we take the path of moving away from interpreting human rights obligations solely within the purview of states. The first, as Clapham (2006) addresses, the worry that holding other bodies accountable to human rights might unduly legitimize them (as in the case of insurgents, etc.). This might hinder humanitarian's ability to remain apolitical, which, as De Ceukelaire and Botenga (2014) point out, has significant benefits we may not want to sacrifice. Additionally, diffusing the duty of meeting the rights to non-state actors or charities may encourage negligent governments to remain so (a point I will discuss in more depth later). However, I would argue, like Clapham (2006), that the world has in many ways already moved on from the state model. The world is shifting and new ways of applying and thinking about human rights are needed. Additionally, the new global health challenges, both present (like the COVID-19 pandemic) and on the horizon (like climate change, and the next pandemic whenever it arrives), provide us significant and overwhelming reason to prioritize global health over the other worries, like subsidizing a lazy state, or giving political power to non-states in unprecedented ways. The times are changing already; we just need to keep up. Thus, to realize the "minimum core obligations" that all people are entitled to under the right, necessitates not only cooperation between states, but sometimes cooperation between aid organizations, INGOs, and states. When states have failed, humanitarian aid organizations may be the only capable bodies to which people can turn for help meeting their basic needs. However, humanitarian interventions carry with them their own unique kinds of ethical risks. Out of respect for the rights of the aid recipients, any humanitarian intervention should be careful to respect the autonomy of the recipients, and avoid unintentional coercion, culturally imperialistic bias, and creating or exacerbating cycles of dependency. 


\section{States of Emergency and Patient Autonomy}

Many altruistic people feel the humanitarian urge to help when others are in need. In that case, they may not be acting because they feel that they are under obligation to meet another person's right. But even if acting out of altruism, in helping others, one assumes a responsibility not to violate the recipient's rights.

Humanitarian aid is often motivated by laudable feelings, like compassion and empathy, but these are not always the best guides to effective or just methods of aid. A doctor may see a person choking, and rush to help. But because of informed consent, the patient has a right to refuse care, or sign a "Do Not Resuscitate" (DNR). Hypothetically, if a doctor knowingly resuscitated a person who signed a DNR, the doctor would be disrespecting the patient's autonomy. DNRs protect patient's wishes, and override what the doctor might otherwise wish to do or think is right.

In emergency situations, ascertaining the wishes of the person in need can be difficult or impossible, and analogous situations arise during urgent humanitarian interventions as well. For example, in countries like Haiti and Nepal, which have had recent devastating earthquakes that destroyed or disabled large parts of their infrastructure, the people were in obvious need of help, but lacked the ability to set the terms on which the help was given. The historian Bertrand Taithe (2017) discussed the problems that emerged in the wake of the 2010 earthquake in Haiti. Many of the people who rushed to help after the disaster, while motivated by altruistic intentions, were not actually highly skilled (or skilled at all) in the areas which were needed. Instead of skilled surgeons, the Haitians were often stuck with retired dentists, or other professionals. Almost any help is preferable to no help at all, but if given the choice, one would of course want effective help. Sadly, in such cases, the recipients of aid are not always given that option. This is one of the areas where things could and should be improved.

When unable to ask the patient about their wishes, doctors usually make assumptions based on what they imagine a reasonable and informed person would wish. This courtesy should be extended to the recipients of aid, but sometimes it is not. The old cliché may say that beggars can't be choosers, but beggars still have basic human rights. Good intentions are not enough to ensure good outcomes, and thus those participating in humanitarian health interventions ought to insure that they have more than just good intentions to offer.

\section{Unintentional Coercion and "Unrefusable Offers"}

Lisa Fuller (2012) presents several scenarios where well-intentioned health INGOs can nevertheless undermine the recipient community's agency, and unwittingly inflict suffering in the form of cultural imperialism. As she describes, cultural imperialism is wrong, because it causes suffering, makes people worse off, and undermines the autonomy of individuals and communities (Fuller 2012). For these reasons, it seems especially important to try to avoid committing cultural imperialism if one's sincere aim is to make others better off and more empowered, as it is in the context of most health INGOs.

Without special care or forethought, Fuller worries that the unequal power dynamic between an INGO and the recipient community will result in what she calls 
"unrefusable offers." She describes scenarios where recipient communities may be forced to choose between upholding their values and receiving help, and argues that making such offers is unethical. This presents a dilemma for international interventions on behalf of human rights, for many methods of intervention may produce similar scenarios.

Fuller gives two hypothetical examples in her paper. First, an INGO runs a feeding center that, for the sake of cost-effectiveness, wishes to prioritize providing food to children, rather than the elderly in the community (Fuller 2012, 215). The INGO runs into trouble when the community's values conflict with this order of serving. The community wishes that its elders be given the priority. The INGO's cost-effectiveness will go down if they comply, and in the absence of the INGO's accommodation, the people are left with the choice to either go against their traditions and act in a way they perceive to be disrespectful of their elders, or go hungry (Fuller 2012, 215).

In all likelihood, less people overall will actually come to the feeding center than would have if there was no such value conflict. This amounts to a lose-lose situation. As Fuller says, “as a purely practical matter, many projects simply won't work efficiently - or at all - if they are designed in a way that conflicts with the dominant cultural beliefs and social conventions of the recipients" (2012, 215). Cultural sensitivity is not only important for the sake of behaving ethically but also for the sake of efficacy too. Without taking into account the cultural landscape, the INGO will not be able to achieve its goals effectively or efficiently.

In her second example, Fuller describes an INGO that wishes to provide antiretrovirals to an HIV-afflicted community. Complications arise from the fact that the antiretrovirals are known to negatively interact with local herbal remedies provided by a traditional healer (Fuller 2012, 216). The INGO has a three options - (1) they can undermine the healer and convince the patients to stop taking the herbal remedies; (2) the INGO could relocate to serve a different community without a similar risk of culture loss; or (3) the INGO could attempt to convince the traditional healers of the negative interaction between the antiretrovirals and traditional remedies (Fuller 2012, 232).

Fuller argues that the first two options are culturally imperialistic, sending the message that the recipient community must either conform to the INGO's values or go without help. The third, which she fleshes out into what she calls an "iterated process of reciprocal negotiation" later in her paper, is the only option which avoids the imperialistic harm (Fuller 2012, 214). In this process, both parties, through dialogue, work out a set of shared beliefs and values and discuss how to proceed, and importantly, both parties stand on equal footing in the negotiation (Fuller 2012, 230).

In her article, Fuller foresees an objection to her ideas from Susan Moller Okin (Fuller 2012, 234-236). Okin suggests that "interactive" approaches, such as Fuller's, will fall short in contexts where "oppressed people have internalized their oppression" (Fuller 2012, 234). Fuller responds to this by implying that Okin only raises questions about "adaptive preferences" and "false consciousness" when the views in question conflict with her own (which are distinctly Western), and that such thinking only encourages dismissing the views of the poor and oppressed without taking them seriously (Fuller 2012 , 235). She admits that her proposed method is not the most efficient available, but continues to assert that it is the most ethical (Fuller 2012, 235).

Fuller may or may not be right about Okin's sincerity in raising the objection, but regardless of Okin's motives or private attitudes, the existence of internalized 
oppression remains a real possibility. Because of this potential, determining what may be in the best interest of a given recipient community is likely to be more complicated than simply asking about their wishes or needs. In fact, one need not speculate about internalized oppression to recognize that people are not always perfectly forthright or even fully aware of what is in their best interests. For example, within a doctor-patient relationship, the patient may or may not be forthcoming about their health status or health-related activities and needs, especially if there is shame attached. Where stigma is present, for instance, patients may be less likely to admit to risky sexual activity, drug use, etc. Ideally, doctors can try to foster trust between themselves and their patients to minimize this gap, but it can be hard to close entirely. This dynamic can play out between INGOs and recipients of aid as well, meaning that even when certain forms of aid are sorely needed, the community may be reticent in acknowledging or asking for certain kinds of help. Thus, I would argue that in at least some cases, Okin may be right to raise this concern, and relying on something like reciprocal negotiation will not result in the best overall outcome.

Fuller seems to think that coercive pressures across cultural boundaries will always be imperialistic, harmful, and therefore wrong and unjustifiable. This is where I disagree. Comparing the "unrefusable offers" she discusses to an imaginary ideal with no culturally imperialistic harm indeed makes these scenarios seem wrong. However, this is not the choice we are faced with in practice-often the ideal scenario is unavailable, despite the best efforts of all involved. This means that in at least some cases, paternalistic and coercive pressure will be less harmful than the alternatives.

Despite this reality, internalized oppression still makes for a deeply problematic basis for human rights intervention. We cannot expect recipients of aid to always express their needs plainly, nor to be perfectly aware of their health needs or the best methods to achieve public health goals. Yet, whether or not the wishes they do express are influenced by "internalized oppression," presuming so as a means to justify intervention that disregards the wishes that the recipients do express is deeply problematic and should be avoided. Thus, from the standpoint of the INGO, it is better to be agnostic about the presence of "internalized oppression" in any given community. It may or may not be present, and may or may not become a complicating factor in the efficacy of aid. But by itself, it is flimsy and indeed suspicious grounds for justifying the disregard of the wishes of the recipient community.

\section{An Appropriate Ethos for Aid}

Human rights, as conventionally conceived, are meant to empower people to stand-up and defend themselves from oppression and undue coercion. Thus, if humanitarian action is carried out in service of people's human rights, and especially if humanitarian organizations and charities can be said to be bound by human rights obligations (as I have been arguing), then any actions or services these entities perform should be similarly aimed at empowering the recipients of aid. Just as the genuine practice of medicine requires sincerity on the practitioner's part-meaning, sincere interest in patient's well-being and sincere belief in the efficacy of the treatments they prescribe. Likewise, to be genuinely engaged in humanitarian efforts requires sincere interest in both the efficacy of one's own methods and sincere respect for the wishes and wellbeing of the recipient. 
If humanitarian aid can be a form of intervention to make up for the unmet minimum core obligations of the right to health, aid organizations need to prioritize the needs and wishes of the recipients above their own ideas about what help they give and how they give it. Too often the recipients are painted as an abstraction, merely vehicles for better off people to feel satisfied with themselves about their own charitable natures, and disasters treated merely as stages on which to play the white knight. We would not accept such behavior from a doctor towards his patient, and neither should we tolerate those attitudes in humanitarian interventions.

Before moving away from this point, it is worth discussing a real example of how cross-cultural interventions can go poorly, and how the intervention could have been improved. The documentary, The Vasectomist (2013), follows an American doctor's campaigns in both the Philippines and Haiti, where he regularly ventures to set up clinics to offer the locals vasectomies. He not only offers these free of charge, but offers a financial incentive for men to come in (ostensibly to compensate them in the case that they have to miss work for the operation). His actions are motivated by his wish to help the poor populations in the respective countries, who often have more children than they can support financially. However, his actions create controversy and anger in many of the locals because vasectomies and other methods of contraception are explicitly forbidden by the Catholic Church, to which most of the locals belong. The doctor's actions create just the kind of value conflict Fuller worries about.

If his motive was to minimize the numbers of children growing up in poverty, offering vasectomies was by no means the only method at his disposal. He could have partnered with local family planning clinics, which teach women how to track their cycles and fertility (a method of family planning considered acceptable in Catholicism). Instead, his choice to offer vasectomies reflected and projected his own beliefs about what is best for the Haitians and Filipinos, in disregard of their own assessment of what was best for them. His actions would have been better received, and perhaps also more effective towards the goal of alleviating poverty, with a better understanding of the values and wishes of the recipient community. Prioritizing dialogue can enable aid workers and the communities they serve to better identify mutual goals and work towards them more effectively. Carried out this way, humanitarian aid more directly fulfils the mission of a human right to health.

\section{Escaping the Cycle of Dependency}

Another concern for humanitarian intervention is that it may become an exacerbating influence. This concern has received considerable attention in the literature surrounding development aid and humanitarian interventions (see Moyo 2001; Lentz et al. 2005; Assal 2008; Dübgen 2012; Cunningham 2012, among others). Some researchers, like Lentz et al. (2005), found no causal link between the provision of food aid and dependency. Yet others, like Assal (2008), have found evidence to suggest that humanitarian aid has little chance of achieving its development goals (at least in Eastern Sudan, where the data was gathered), observing that although NGOs created structural changes, aid did not produce positive coping strategies and instead created dependence in the NGOs themselves. Still more recently, Cunningham (2012) has found that humanitarian aid regimes can become their own worst enemies (citing the response to the earthquake in Haiti as an example). Certainly, humanitarian aid campaigns can run into many complications that create 
inefficiency, risk the creation of cycles of dependency that undermine the aid mission itself. Further, the stigma that aid culture creates should not be ignored, since it can discourage future investors and actually reinforce the nation's Third World status (Moyo 2001). There is also a risk that insincere regimes may use the presence of aid as an excuse not to spend their own resources on health, thus leaving people in perpetual vulnerability. Foreign aid both ought to be and can be done better, and one way to solve this is to formulate well-defined duties and regulations that make clear that humanitarian aid can only be provided for short spans of time (Moyo 2001).

Indeed, in his article "Minimum Core Obligations: Human Rights in the Here and Now," John Tasioulas (2017) describes this very thing as a key feature within the language of ICESCR. While a state may request and accept aid whenever it is unable to realize all the demands of the human right to health, the state must simultaneously take steps that would eventually remove the need for aid. In line with this, INGOs that step in to help unmet health needs must be mindful to carry out the aid campaigns in ways which can enable the recipient community to eventually stand on its own. Aid can only ever act as an interim remedy, and is insufficient on its own without the state's commitment to "progressive realization." Again in the words of Wolff, "the point of establishing rights is to try to rebalance the power relationship, and to produce longterm, reliable structures that will remove the need for humanitarian concern in the future" (Wolff 2012, 15-16). Part of rectifying the situation, and thus part of what aid organizations ought to help accomplish, is building the political structures which will take over in their work.

\section{Patterns of Violation: When and How (Non-)State Actors Should Respond}

Unmet needs are not the only situations in which interventions on behalf of health are called for. One might hope that health is such an obvious good that even the most totalitarian regimes would see the practical benefits of looking after the health of their people. Unfortunately, violations can and do occur. What role then (if any) do INGOs play in those cases?

When violations do occur, I will argue that any action in the name of the human right to health is constrained in its function as justification for intervention in a way that not all human rights are. If intervention is supposed to be on behalf of people's health, the form of intervention itself must not make those people's health materially worse. Because of this, INGOs continue to serve an important function on behalf of the human right to health in the case of outright violations, not just unmet needs. Some human right abuses (e.g., genocide) may indeed justify intervention by other states (as is the conventional thinking), but this will almost never make sense on behalf of the human right to health for several reasons. War (even a just war) will make the health conditions of those people worse. If the point of persuading such a state to meet its population's right to health is to actually improve the health of those people, then starting a war in which many of those people will suffer and die seems decidedly wrongheaded.

To avoid accusations of hypocrisy and to effectively defend the value of health, any intervention (especially if carried out by a non-state actor) must take every available precaution to ensure that the intervention itself does not actually make the supposed 
beneficiaries worse off. Because of this unique character of the human right to health, INGOs are often in a better position to accomplish this than official state agencies. Where intervention by a state may either meet with backlash or worsen the situation on the ground, the "softer" approach and alternative means and tools available to INGOs can make them more effective in addressing some forms of violations.

To be clear, I am not arguing that states cannot or should not ever take action to protect the human right to health. Indeed, the state's status of primary duty bearer ought to remain in place. The questions that face us here are the following: What ought to be done when states violate the right to health? How can we distinguish which violations call for what kind of response and by whom?

What form of interventions seems logical, ethical, and appropriate depends on the manner in which violations have occurred. States can violate the right to health along several patterns: (1) through negligence and mismanagement of resources, (2) through systemic bias that unfairly privileges or disadvantages members of certain groups within the society, (3) through the refusal of aid, and (4) through active persecution. Each of these patterns of injury requires a different kind of response from the international community and justify different kinds of interventions (and from different kinds of duty bearers).

\section{Systemic Bias}

Systemic bias leads to the failure to treat all people with equal human dignity, whether the bias stems from racism, sexism, or xenophobia. The consequences can include inequalities in access to healthcare and basic resources, which certainly constitute a violation to their right to health. Bias of this kind can shorten the lives of the stigmatized and disadvantaged. One example of the negative effects of such bias is the way that the AIDs crisis has been handled over the years. During the AIDS crisis in the 1980s in the USA, homophobia led the government to delay taking actions that could have helped prevent its spread. Discrimination towards people with AIDS and HIV due to a suspected connection with homosexuality continues to be an obstacle to treatment and prevention in many areas, including Russia and parts of Africa.

Here, heavy-handed forms of intervention are likely to aggravate international relations. But other states can and should still communicate their disagreement and displeasure about such activity. Condemnation from the international community, combined with information campaigns (carried out by INGOs) that attempt to dispel the beliefs fueling the systemic bias, over time, can weaken and eliminate that bias. In such cases, intervention from non-state actors may be more welcome and effective. If an American state agency were to openly criticize or put pressure on HIV discrimination within Russia, for instance, it would be likely to trigger backlash. The perception of American imperialism, along with Russia's own national rivalry with the USA, may trigger more entrenchment of the very systemic bias that is the target of intervention.

\section{Malicious Negligence}

While systemic bias often stems from deeply seated cultural beliefs, there are other possible sources and motives behind violations of the right to health. One of those is what I will call malicious negligence. Negligence on the part of the state and the mismanagement of resources leading to negative health consequences for its population 
is bad enough to prompt some kind of interventions from humanitarian organizations. However, sometimes this negligence is not born of ignorance, but born of selfishness on the part of those in power-which may be justifications for stronger forms of intervention.

For example, we can look at Libya when Gaddafi was in power and North Korea under the Kim family. These regimes disproportionately spend the nation's resources on the leader's personal enrichment and on military measures which help maintain the regimes' power, at the expense of the basic needs and health of their population. In this context, we are not necessarily dealing with a difference in beliefs; North Korea does not need to be convinced that people need food. However, the regime has made the decision that these basic needs are less important than the Kim family's continued power.

Cases like this present an ethical puzzle. On the one hand, aid would clearly benefit the people, but on the other hand, it could help perpetuate the regimes unjust autocratic rule. Given how the regime treats its own people and the threat that it poses to outsiders, acting in ways that enable the regime to sustain itself seems to have consequences potentially as dire as not acting. If a hypothetical regime keeps its people in a state worse than death, then aid which helps perpetuate that would be worse than no aid at all. In cases like this, aid from an official agency may unwittingly lend legitimacy to such a regime (a worry similar to the one Clapham (2006) raises in the context of signing human rights agreements with insurgents and rebel groups). Here, humanitarian effort from a non-state actor might both be more welcomed by the negligent regime, and avoid the diplomatic complications that would face a state actor.

\section{The Unable and Unwilling}

While states like North Korea and Gaddafi's Libya were negligent in their duties toward their people, they still display a willingness to accept help from outside (as North Korea accepts aid regularly from China and in the past from other nations as well). But what can be done when the state is both negligent and unwilling to accept aid?

This is the case Venezuela faces. Venezuela lacks the resources to meet its people's fundamental rights to health, but those in power, Maduro, have refused to accept humanitarian aid. Purely on behalf of the Venezuelan people's health, it might be possible to justify disregarding the government's sovereignty, but only in the process of offering aid measures. For example, perhaps it would be possible to air drop food and resources despite Maduro's refusal. If this were carried out by other states, it might be perceived as aggression can escalate conflict or worsen the situation. Non-state actors may be able to provide assistance without triggering as much resistance.

\section{Persecution}

The most severe and unambiguous way that states can violate their people's right to health is through active persecution. Often, as events play out, the most severe violations of the human right to health are accompanied by violations of other rights as well. For one current example, the Rohingya in Myanmar are not only being denied access to healthcare, but they are being actively persecuted to a much more severe degree (murdered, chased out of their homes, denied citizenship, etc.). In a case like 
this, it would seem odd to justify intervention on behalf of the Rohingya's right to health, when so many other seemingly more pressing issues are available. The nature of the violation in this kind of case, being intentional, urgent, and severe, warrants the strongest form of intervention. While the aid of INGOs is not necessarily precluded in such cases, a response from other states via more conventional political channels is also required by the human right. Condemnation of the violence and political pressure to stop the killing cannot be effectively done through INGOs alone.

Where violations of the right to health can be addressed with education campaigns, INGOs and charities may often be better suited to step in than official state agencies because of their unique apolitical or quasi-political status. However, in more severe and urgent cases, where there is justification and need for more forceful intervention, states remain the best equipped. The more severe and immanent the harm, the more justification there is for intervention by other states. But for anything less than outright persecution, whether systemic bias or malicious negligence, campaigns of education are close to the only option ethically available. Other forms of intervention are more likely than not to make the lived situations of the supposed beneficiaries worse, rather than better (at least in the short term).

\section{Culture Loss and Health Gain}

While I think that most of the time interventions which are culturally sensitive are not only the most ethical but also the most effective methods, there are cases where the two come apart. Respect for autonomy is important, yet in the realm of health and medicine, it is at least sometimes outweighed by the commitment to non-harm. Similarly, while I support the idea that cultural sensitivity is important to consider-both for the sake of efficacy and respect for people's autonomy - it is sometimes superseded by the ethical duty to prevent severe and imminent harms.

Fuller attempts to deal with this issue in the way she defines her terms. She defines culture as "that complex whole that includes knowledge, belief, art, law, custom, and any other institutions, habits, and signifying practices acquired by people as members of particular societies and passed on from generation to generation by means of education, the family and tradition" (Fuller 2012, 216). Further, Fuller (2012) goes on to distinguish between two types of belief, factual and moral:

factual beliefs [are] those that relate to whether or not certain medicines and medical treatments are likely to make people better off by curing them, alleviating pain, or extending life... moral and religious beliefs ... are those that concern right and wrong - that is, which actions are morally prohibited [or] permissible [including] honor, modesty, and appropriate public and private behavior [and] someone's assessment of what would improve his or her welfare. (219)

Fuller (2012) also says, "if a norm or practice has very little or no value...then acting against it will not count as a significant evil" (223). Here, I think Fuller is hoping that the factual/moral divide will enable the most serious conflicts to be avoided. But in the realm of health, the factual and moral can be very difficult, if not impossible, to separate. Thus, when such conflicts do arise, we need to be able to determine which path leads to greater harm. 
Some cultural conceptions of both health and healthcare fail to meet the minimum standard of the human right to health. When intervening on the behalf of health, states and/or humanitarian organizations may need to confront deeply embedded cultural beliefs about health and medicine that range from wrong, to inadequate, to outright harmful. Considering what Kymlicka and Sullivan, as well as Fuller, have argued, attempts to convert people out of these beliefs can be problematic - especially when working across borders and when the power dynamic is imbalanced.

Fuller is concerned that humanitarian interventions are carried out by organizations "harboring a ... Western, liberal agenda and [which are] insufficiently engaged with... the communities they serve" (Fuller 2012, 214). While I agree with her that interventions which fit that description cross into the unethical, it is also true that some traditional beliefs and practices are in reality harmful. Some cultural practices, such as female genital mutilation (FGM), can severely harm the women subjected to it. FGM has no known health benefits, and many complications, immediate and long-term. Just some of the immediate complications include "fatal bleeding, acute urinary retention, urinary infection, wound infection, septicemia and even the potential for the transmission of hepatitis or HIV depending on the instruments used" ("Care of Women with Female Genital Mutilation/ Cutting, n.d."). Later complications can include strictures in the urinary and genital tracts, and incontinence. There can also be psychological consequences such as depression or posttraumatic stress disorder. A practice like this clearly goes against the entitlements described in General Comment 14, as "the right to control one's health and body, including sexual and reproductive freedom, and the right to be free from interference, such as the right to be free from torture, non-consensual medical treatment and experimentation."

Would it be culturally imperialistic to coerce another group out of such a practice? FGM is not justified on inaccurate factual beliefs. The explicit reasons people give for subjecting their daughters to FGM are intimately tied to the system of beliefs around chastity and sexuality, marriageability, and appropriateness in the cultures which practice it. Thus, it seems Fuller would place it in the moral belief category, and yet the facts indicate its detrimental health effects.

Because of the harm involved, I would argue that there is at least some justification for the application of pressure to limit or stop the practice. But depending on the kind of pressure involved and where it comes from, it may fail to be effective. Because of the deep cultural embedding of such a practice, many aggressive forms of intervention to stop FGM have been met with resistance, which only entrenches the practice further. When pressure is perceived to come from "outsiders," who do not understand the communities' ways or values, it can become a flashpoint of cultural conflict. Instead, campaigns of education and information that slowly create a sub-population that does not engage in FGM are likely to be more productive, even if they can feel frustratingly slow. Eventually, once a critical mass is reached, the reasons for holding on to the practice will be gone.

\section{A Rule of Rescue}

More extreme cases, like honor killing, reveal cracks in negotiative approaches, like Fuller's. Whenever an active form of persecution violates people's right to health, time is of the essence. Negotiative approaches require time, but time in such cases is not realistically available if people are at risk of immediate and irreparable harm. Under such pressures, we can appeal to a kind of rule of rescue, which excuses some degree of 
imposition upon another culture and bypasses negotiation. In the end, coercion and cultural imperialism both constitute a form of harm, but so do some cultural practices. Reciprocal negotiation presents a helpful path to resolving some standoffs between conflicting cultural values. A political equivalent to the rule of rescue is helpful in others. Both have drawbacks and downfalls. However, in the process of chasing the ideal of global justice, often the non-ideal is the only way forward.

\section{Conclusion}

Human rights exist to motivate institutions to respond when the fundamental components of what makes life worth living are threatened, and in the case of health, threats can arise from human action (and inaction) as well as natural forces. Threats to health do not stop at political boundaries, and thus a commitment to protecting health (and the duty to respond) must extend beyond national borders as well. These facts, combined with its status as a positive right, means that in addition to responding to outright violations, intervention can also be obligated and justified on behalf of unmet minimum standards.

When the primary duty holders are unable to meet those minimum standards, the obligation diffuses to other capable bodies, which can include humanitarian organizations and INGOs. This unique dynamic necessitates additional ethical strategies to guide the actions of such organizations when acting in lieu of the primary duty holders. With the guidelines I have provided here, it should be clear that it is both necessary and possible to respond to the issues of global health in a way that respects the autonomy of aid recipients and minimizes the risk of exacerbating cycles of dependency, while still offering relief for unmet health needs. As with other human rights, in scenarios where states are unwilling to discharge their duties regarding the human right to health, political pressures from other states are warranted. But these pressures will be constrained by the need to avoid making the actual health conditions worse for the populations in question. Here, again, humanitarian organizations can play an important role on behalf of the human right to health and can fill in the gaps when action from states is missing or ineffective.

Acknowledgements I would like to thank Jonathan Wolff and Andres Luco for their extensive feedback on earlier drafts.

Availability of Data Not applicable.

\section{Declarations}

Conflict of Interest The author declares no competing interest.

\section{References}

Assal, M.A.M. (2008) "Is it the Fault of NGOs Alone? Aid and Dependency in Eastern Sudan." Chr. Michelsen Institute, Sudan Working Paper SWP: 5.

Beitz, Charles. (2009) The Idea of Human Rights. Oxford University Press. 
Bellamy, Alex J. (2006) "Whither the Responsibility to Protect? Humanitarian Intervention and the 2005 World Summit." Ethics and International Affairs, 20 (2):143-169.

Buchanan, Allen E. (2010) Human Rights, Legitimacy, and the Use of Force. Oxford: Oxford UP.

"Care of Women with Female Genital Mutilation/Cutting (n.d.)." Swiss Medical Weekly. Swiss Med Wkly, 6 Jan 2011. Web. 9 Jan 2014.

Clapham, Andrew. (2006) "Human Rights Obligations of Non-State Actors in Conflict Situations." International Review of the Red Cross, 88(863): 491-523, 2006.

Cunningham, O. (2012) "The Humanitarian Aid Regime in the Republic of NGOs: The Fallacy of 'Building Back Better," Josef Korbel Journal of Advanced International Studies 4: 101-126.

DeCamp, Matthew. (2005) "Responsibility for Global Health." Theoretical Medicine and Bioethics, 27(1):95114.

De Ceukelaire, Wim, and Marc Johan Botenga. (2014) “On Global Health: Stick to Sovereignty." The Lancet $15,2014$.

Dübgen, Franziska. (2012) “Africa Humiliated? Misrecognition in Development Aid.” Res Publica, 18(1):6577.

Emerson, Claudia and Peter Singer. (2010) "Is there an ethical obligation to complete polio eradication?" Perspectives: The Art of Medicine, 375, 9723.

Fuller, Lisa. (2012) "International NGO Health Programs in a Non-Ideal World: Imperialism, Respect, and Procedural Justice." Global Justice and Bioethics. Ed. Joseph Millum and Ezekiel J. Emanuel. Oxford University Press, New York.

“General Comment 14.” Refworld.org. N.p., n.d. Web. 01 June 2014.

"International Covenant on Economic, Social and Cultural Rights." International Covenant on Economic, Social and Cultural Rights. N.p., n.d. Web. 01 June 2014.

Lentz, Erin, Christopher B. Barnet, and John Hoddinott. (2005) "Food Aid and Dependency: Implications for Emergency Food Security Assessments.” IFPRI Discussion Paper No. 12-2.

Moyo, Dambisa. (2001) "Why Foreign Aid Is Hurting Africa." The Wall Street Journal. 1-5.

Peterson, Richard T. (2006) "Human Rights and the Politics of Neo-Colonial Intervention." Radical Philosophy Today, 211-234.

Singer, Peter. (1972) "Famine, Affluence and Morality." Philosophy and Public Affairs, 1(3):229-243.

Singer, Peter. (2009) The Life You Can Save. Random House.

Sreenivasan, Gopal. (2012) "A Human Right to Health? Some Inconclusive Scepticism." Proceedings of the Aristotelian Society Supplementary Volume lxxxvi.

Sullivan, William M., and Will Kymlicka. (2007) The Globalization of Ethics: Religious and Secular Perspectives. Cambridge: Cambridge University Press.

Taithe, Bertrand. (2017) "Humanitarianism and Medicine: Past and Present." 9 ${ }^{\text {th }}$ European Spring School on the History of Science and Popularization, Institut Menorqui d'Estudis, Mahon, 20 May.

Tasioulas, John. (2009) “Are Human Rights Essentially Triggers for Intervention?” Philosophy Compass, 4(6):938-950.

Tasioulas, John. (2017a) “The Minimum Core of the Human Right to Health.” World Bank, Washington, DC. (C) World Bank. https://openknowledge.worldbank.org/handle/10986/29143 License: CC BY 3.0 IGO.

Tasioulas, John. (2017b) "Minimum Core Obligations : Human Rights in the Here and Now." World Bank, Washington, DC. (C) World Bank. https://openknowledge.worldbank.org/handle/10986/29144 License: CC BY 3.0 IGO

"The Universal Declaration of Human Rights, UDHR, Declaration of Human Rights, Human Rights Declaration, Human Rights Charter, The UN and Human Rights." UN News Center. UN, n.d. Web. 29 Aug. 2014.

The Vasectomist. (2013) Dir Jonathan Stack, Saralena Weinfield.

Viehoff, Daniel. (2013) “The Right Against Interference: Human Rights and Legitimate Authority." Law and Ethics of Human Rights, 7(1):25-46.

Wolff, Jonathan. (2012) The Human Right to Health. New York: W.W. Norton.

Publisher's Note Springer Nature remains neutral with regard to jurisdictional claims in published maps and institutional affiliations. 